\title{
Development of an Automated System for Sampling Crop Material from a Forage Harvester
}

\author{
J. P. Long, D. R. Buckmaster
}

\begin{abstract}
A modular, computer-controlled sampling system was developed to directly sample chopped forage material from a forage harvester spout. Pneumatic cylinders powered a deflector flap to redirect crop material from the spout. A hydraulic cylinder compressed deflected forage material into 35.6-cm long, 10.2-cm diameter PVC pipes, which served as miniature test silos. Timing of the pneumatic and hydraulic actuators was controlled by a programmable microcontroller. The control system included three operator inputs: travel speed, row length, and number of samples along the row for each silo; this provided flexibility to adapt to different harvesting situations. In two experiments, test-silo samples fermented for 48 days and then were separated into six size fractions. In the first experiment, a side-by-side comparison with a self-propelled plot harvester, statistically significant differences in the mass fractions of medium and small particles (indicated by low p-values in the range of 0.1 to $<0.001)$ were found between samples collected by both machines and their respective controls. No differences in the mass fractions of large particles were found. In the second experiment, the performance of the modular sampling system in sampling corn chopped at two theoretical lengths of cut (6.35 and $19.1 \mathrm{~mm})$ and two whole-plant moisture levels (approximately 70 and $60 \%$ w.b.) was evaluated. Some significant statistical differences between automatic sampling and manual sampling were present; however, trends were inconclusive. The magnitudes of mass percentage and characteristic particle size differences were at most $8 \%$ and $1.6 \mathrm{~mm}$, respectively.
\end{abstract}

Keywords. Forage harvesting, Forage sampling, Particle size distributions, Electronic control, Pneumatics, Hydraulics, Forage plots, Plot harvesting, Miniature Silos, Laboratory-scale silos.

$\mathrm{F}$ Torage crops such as corn and alfalfa are extremely important components of ruminant rations. Whether they are fed as hay or silage, forages provide cows with carbohydrate, protein, and digestible fiber elements that are critical to the health and productivity of meat and milk producers. Seventy-five percent of the NDF in a cow's diet should come from forage (National Research Council, 2001). For dairy farmers, high milk production is needed for profitability, which requires economically high yields and high quality from their forage crops.

Corn silage is a very popular high-energy feed source for dairy cows. Consequently, a significant amount of the corn grown each year in the United States is chopped for silage (88 million tonnes from 2.41 million ha, average for 1997-2000; National Agricultural Statistics Service, 2001). Because silage production plays such a key role in agriculture, each year, researchers in industry and at public institutions and universities plant hundreds of hybrids in

Article was submitted for review in May 2002; approved for publication by Power \& Machinery Division of ASAE in January 2003.

Mention of a proprietary product does not constitute an endorsement or recommendation for its use by the Pennsylvania State University.

The authors are Judson P. Long, ASAE Member Engineer, Senior Associate Engineer, Caterpillar Inc., Mackinaw, Illinois; and Dennis R. Buckmaster, ASAE Member Engineer, Associate Professor, Pennsylvania State University, Agricultural and Biological Engineering, University Park, Pennsylvania. Corresponding author: Dennis R. Buckmaster, Pennsylvania State University, Agricultural and Biological Engineering, 230 Agricultural Engineering Building, University Park, PA 16802; phone: 814-865-3392; fax: 814-863-1031; e-mail: drb3@psu.edu. test-plots in order to study their characteristics and qualities such as disease resistance, yield potential, and nutritional content. These plots are often 8 to $10 \mathrm{~m}$ in length, but are sometimes longer. For corn, they are usually two to four rows wide, but often only a single row is harvested for data collection. For variety trials, replicate plots of each hybrid are usually planted in numerous locations in a field. Generally, variety trials are also replicated in multiple locations. For corn silage hybrids, both yield and chemical analyses are important; therefore, a study may have many replicate plots that need to be harvested in a timely manner for accurate comparison of the hybrids.

For years, the most common method of harvesting test plots, especially for row crops such as corn, was by hand. Hand-cut stalks would be chopped, then weighed and sampled. This very time-consuming and labor-intensive process led to numerous efforts to construct self-propelled test-plot harvesters. Many types have been developed and used over the past four to five decades to harvest alfalfa and grass crops, corn, sorghum, and other row crops. These machines have varied considerably in size, configuration, type of propulsion, and function.

One of the earliest documented efforts to develop a plot harvester was published by Austenson (1958); a commercial pull-type flail chopper was modified to collect chopped material from the spout. During the 1960s, numerous test-plot harvesters were developed for harvesting alfalfa and hay plots; most were modified flail mowers. Many of these machines required the operator to walk behind (Allen et al., 1968; Collins et al., 1969; McCormick and Hoveland, 1971), while some were outfitted so the operator could ride on the machine (Miltimore et al., 1961; Paterson and Browning, 1962; Buker, 1967). More recent machines have 
had various collection schemes; some collect the harvested crop and some also weigh the material. A few have incorporated electronic data acquisition systems. Some of the more recent machines were constructed around modified flail mowers or commercial swathers for harvesting hay or grass plots (Barnes et al., 1984; Pearson and Robinson, 1994), whereas others were built around more conventional types of forage harvesters with cutterheads and shearbars for harvesting plots of corn or sorghum (Mains and Major, 1983; Frerichs et al., 1993; Pedersen and Moore, 1995). Other machines could be outfitted with either a hay crop or row crop harvesting attachment (Swallow, 1967; Hunter et al., 1974). A few wagons have also been developed to assist with plot harvesting (Caddel et al., 1982; Kraus et al., 1993).

Most test-plot harvesters developed over the past four to five decades have been either self-propelled or tractorpulled, and have included means of collecting and weighing the total amount of material harvested from a plot. While a few commercially produced self-propelled (SP) plot harvesters have been developed to automatically collect crop samples, this ability is not widely available and hand sampling is generally still required. A major step to increase the efficiency and accuracy of forage sampling would be the development of a reliable modular sampling and packaging system that eliminates hand "grab" or "scoop" sampling; such sampling can be particularly poor if the sample is collected from a wagon or truck after pneumatic conveying of the forage through the spout since particle size separation occurs. As yield monitors for forages become available, the ability to calibrate the sensors will be important. An automatic, consistent sampling device may be required.

\section{OBJECTIVES}

The overall goal of this project was to design, develop, and fabricate a modular system to automatically collect chopped forage samples from a forage harvester. Objectives related to this overall goal were to design and develop a modular system which:

- Can be adapted to existing test-plot harvesters and commercial forage harvesters with minimal modifications.

- Can collect a representative forage sample (approximately $2.5 \mathrm{~kg}$ ) under varying conditions - namely high and low crop moisture content, and long and short lengths of cut.

- Can pack the sampled crop material into a miniature test-silo.

- Has the flexibility to be used in a wide variety of operating conditions (i.e., different harvesting speeds, varying field and/or plot lengths, and varying crop yields).

\section{Design of Modular Sampling System \\ DESIGN OVERVIEW}

The sampling system was mounted on a New Holland model 707 forage harvester with a model 707R single row corn head (fig. 1). A Deutz-Allis model 6250 tractor $(37 \mathrm{~kW})$ was used to support the chopper, and power it via the PTO. The sampling system was mounted from the $10.2-\mathrm{cm}$ square support tube that holds the chopper out to the right side of the tractor. Sampling system components were mounted onto a deck frame constructed from steel angle and flat stock. The

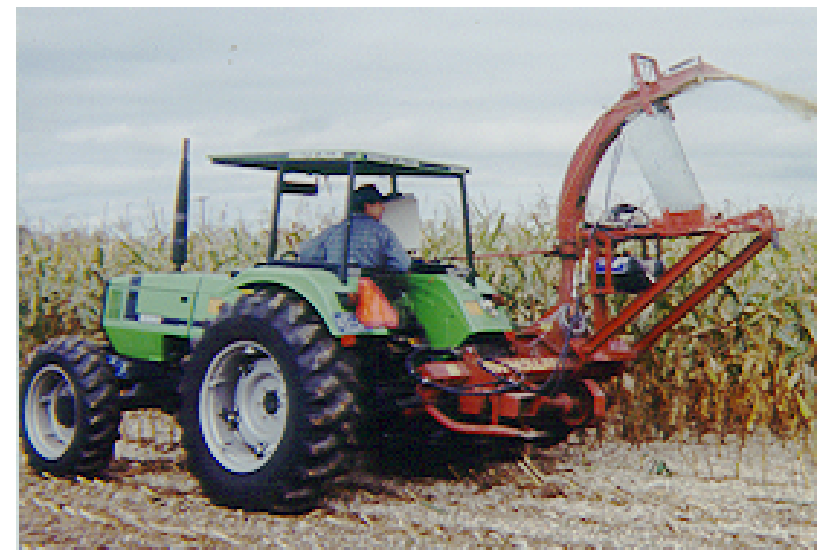

Figure 1. New Holland 707 harvester with the automatic (modular) sampling system.

deck was supported by a vertical steel tube in the front and four pieces of aluminum $\mathrm{C}$-channel in the rear (two per side).

The system was designed to sample forage directly from the crop stream using a steel deflector flap mounted inside the forage harvester spout (fig. 2). Two double acting pneumatic cylinders, controlled by a three-position, closed-center, solenoid operated directional control valve (DCV), actuated the deflector flap so that all of the flow was sampled part of the time. Compressed air for the cylinders was supplied from two 18.9-L air tanks mounted under the deck of the sampling system (fig. 3). The deflector flap, when fully extended, was long enough to slightly protrude through the discharge opening when fully extended. It was $150 \mathrm{~mm}$ long, $158 \mathrm{~mm}$ wide, and $1.98 \mathrm{~mm}$ thick. The deflector was designed so that it could be installed in the spout of a forage harvester with minimal modifications required or be removed if needed. The only modifications made to the harvester spout were a single 12-mm hole drilled on either side (for the flap shaft to fit through), three holes drilled in the bottom of the spout (to secure the lower air cylinder mounting bracket), and a 205-mm long by 160-mm wide opening cut in the bottom of the spout (for deflected crop to fall through). The flap assembly was overlapped with a $175-\mathrm{mm}$ long by $158-\mathrm{mm}$ wide, $0.635-\mathrm{mm}$ thick transition plate so that crop flowing along the curved surface of the harvester spout would be disrupted as little as possible. When the flap was extended, this transition plate helped to make the redirection of material more gradual.

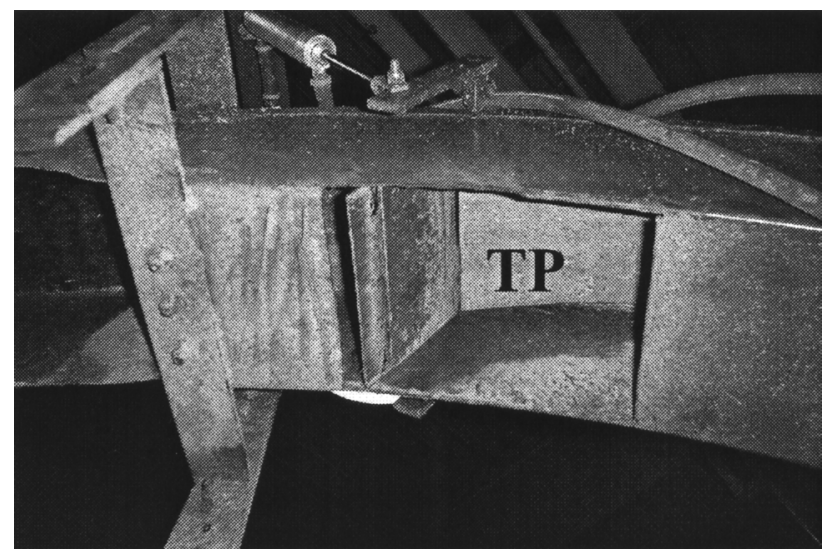

Figure 2. Fully extended deflector flap assembly and transition plate (TP). 


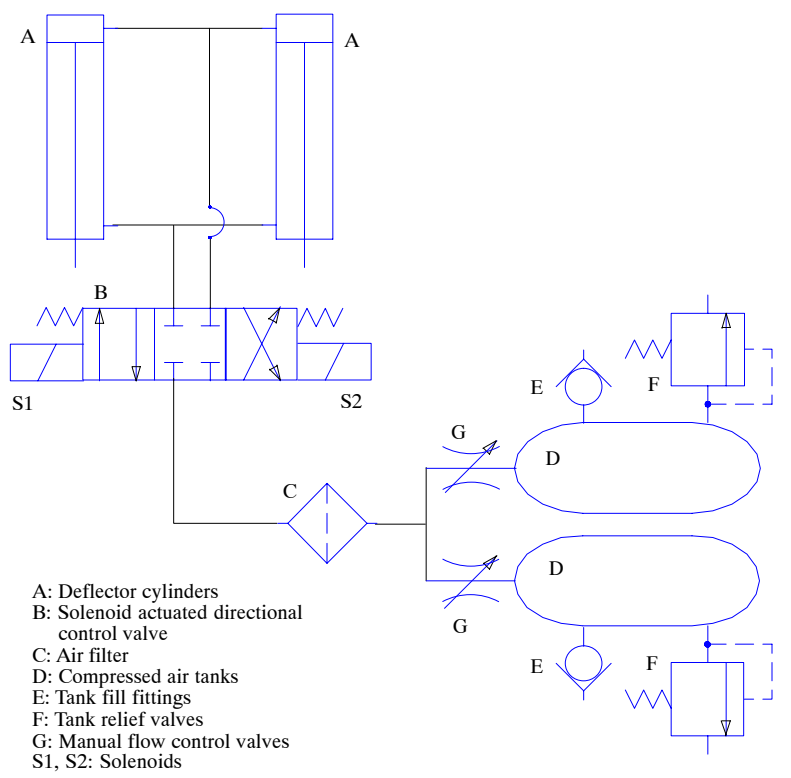

Figure 3. Schematic of the pneumatic portion (flap deflectors) of the automatic sampler.

Deflected crop material fell through a collection chute into a cylindrical packing chamber (fig. 4). The packing chamber was constructed from a $53.3-\mathrm{cm}$ long piece of $10.2-\mathrm{cm}$ inner diameter galvanized steel pipe with a $6.35-\mathrm{mm}$ wall thickness. The top of the chamber was cut away in the center section of the pipe so that crop material could enter without obstruction. Thin steel side plates, 1.98 $\mathrm{mm}$ thick, were welded to the packing chamber tube along the edges of the cutout to serve as a mounting point for the sheet metal collection chute. A double acting hydraulic cylinder with a packing plunger attached to its rod end was mounted in line with the packing chamber (fig. 5). The cylinder compressed the sampled forage through the packing chamber and into a $10.2-\mathrm{cm}$ inside diameter by $35.6-\mathrm{cm}$ long PVC pipe (test-silo) attached to the end (fig. 6). The hydraulic cylinder was positioned so that, at full stroke, the plunger head was still inside the end of the packing tube. In other words, it did not pass through the packing tube and then into the PVC silo, otherwise it would have required the packing tube and silo to have absolutely perfect alignment. Each silo was placed on the sampling system without end caps. After sampling and packing, the PVC pipe was removed and end caps were installed to prevent oxygen from entering the silo. A simple check valve was used to allow gases produced during silage fermentation to escape the PVC mini-silo.

The packing cylinder was controlled with a three-position, closed-center, solenoid actuated, spring-centered directional control valve (fig. 7). A manually adjustable pressure reducing/relieving valve controlled the pressure of the oil supplied to the packing cylinder. Quick coupler connectors were used to connect to a tractor's remote hydraulic ports. Since one objective of this project was to develop a modular sampling system, the hydraulic system was designed to function with tractors having either opencenter (fixed displacement pump) or closed-center (pressure compensated pump) hydraulic systems.

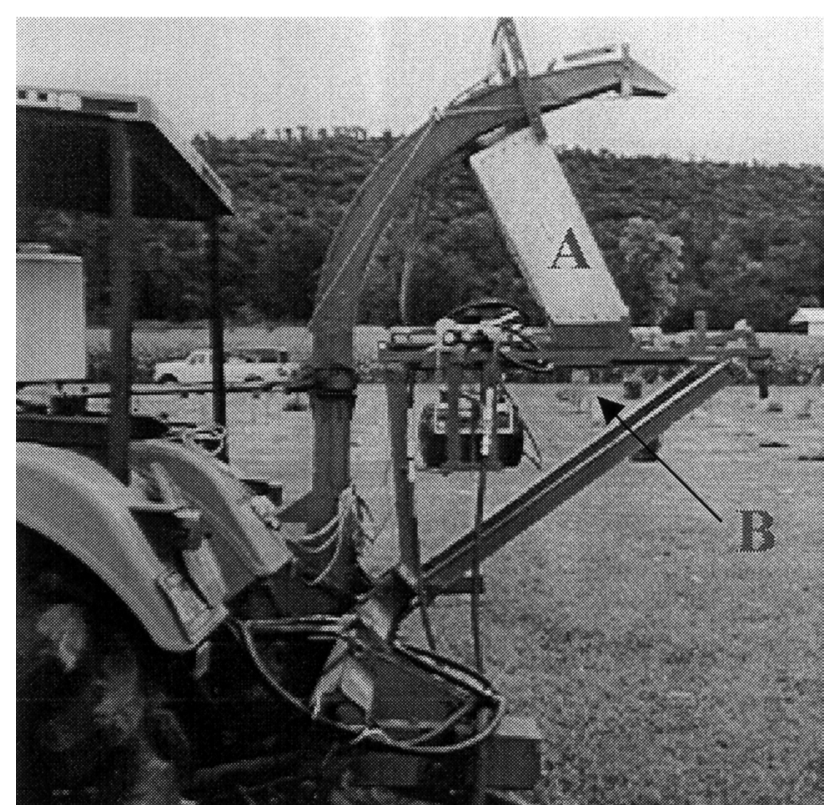

Figure 4. Side view showing collection chute (A) and packing chamber (B) of the modular sampling system.

\section{ConTrol System}

Three of the five hydraulic and pneumatic valves on the sampling system were actuated by $12-\mathrm{VDC}$ solenoids. To provide flexibility in controlling the components on the sampling system, a BasicX-24 (BX-24) microcontroller from Netmedia was chosen. The BX-24 microcontroller was programmed using a version of the Basic programming language that allows complex logic statements and loop structures.

The 12-VDC solenoids on the pneumatic and hydraulic valves were controlled using 3-A solid-state relays. A 12-VDC alkaline lantern battery provided power for the control side of the relays (any alkaline battery with a voltage

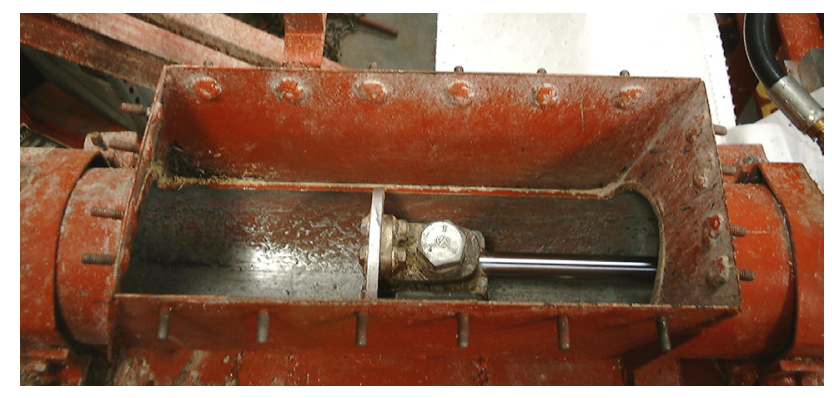

Figure 5. Packing plunger inside packing chamber.

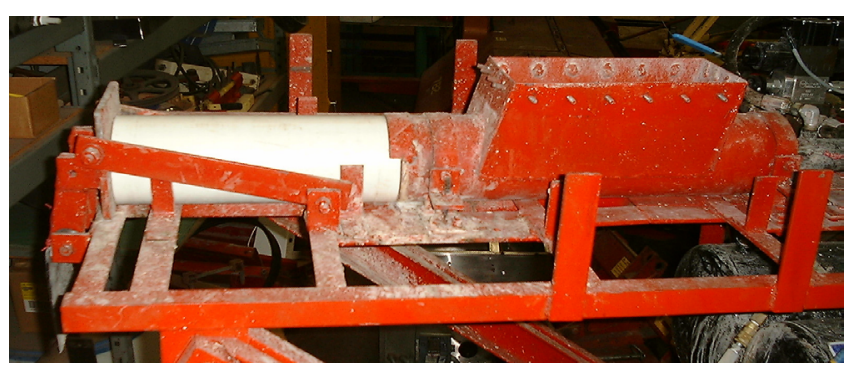

Figure 6. PVC test-silo attached to the packing chamber. 


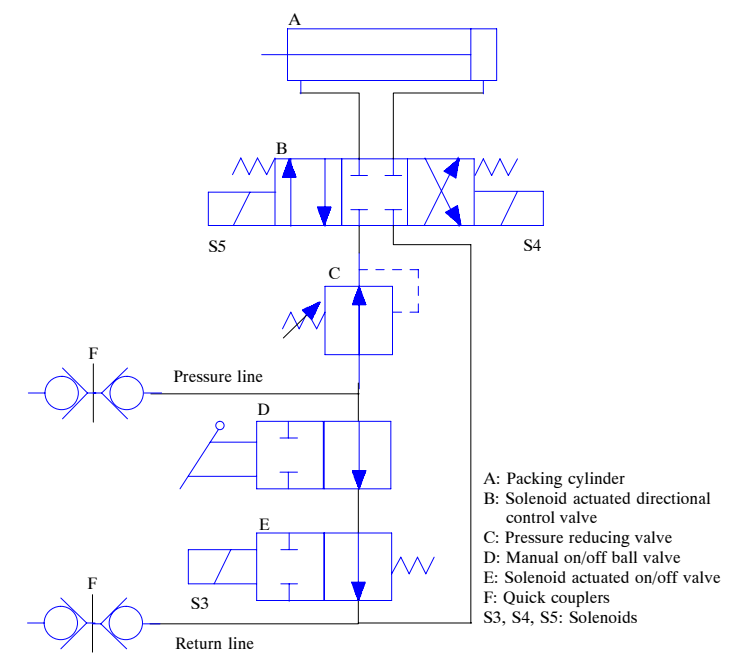

Figure 7. Schematic of the hydraulic portion (packing cylinder) of the automatic sampler.

of approximately 7.5 or greater would work; unreliable operation occurs if voltage drops below 7.5). The control system has three input parameters (not including switches, start buttons, etc.): the desired tractor harvesting speed, the row length to be sampled into one lab-scale silo, and the desired number of samples per silo. The system operator sets these parameters by adjusting three corresponding $10-\mathrm{k} \Omega$ potentiometers; parameter values are displayed in real time on a four-line LCD display. The display includes a built-in bi-directional serial interface and communicates using standard RS-232 serial signals from a host computer or microcontroller. The display includes eight built-in analogto-digital converters (ADCs); three of these were used to read inputs. Once the desired values are dialed in via the potentiometers, an operator pushes the "GO" button to allow the $\mathrm{BX}-24$ to read and store the values. The control program includes upper and lower limits for each of the three quantities, and an error message is displayed if the operator attempts to enter values outside these limits. Once acceptable values are entered, the $\mathrm{BX}-24$ uses them as constants in the control program to compute delays and sampling times. Thus, the system was tractor independent; i.e. it did not require any ground speed sensors to be installed on the tractor; however, the operator must select the proper tractor gear and engine speed to match the ground speed entered via the potentiometer. Most tractors have a sticker or label that lists all gears and the corresponding travel speed for each, and thus proper timing should be easily achieved.

After acceptable inputs have been entered, the operator hits the "GO" button a second time as the harvester enters the plot to begin the sampling and packing sequence. The start of the sampling sequence is delayed until the tractor travels a specified distance (set as a constant in the control program) at the beginning of a plot in order to eliminate any end effects in a row; $5 \mathrm{ft}$ was used for all sampling in this project. After the initial delay, the sampling sequence commences with activation of the pneumatic and hydraulic systems to take the first sample. First, solenoid S1 (fig. 3) is energized to extend the pneumatic cylinders (extending the deflector flap). Flap extension duration was set in the control program to either 0.25 or $0.75 \mathrm{~s}$ (depending on crop yield) to obtain a proper amount of silage per sample and fill individual silos with 7 or 10 samples. After the flap extension period, solenoid S1 is denergized and solenoid S2 (fig. 3) is energized to retract the cylinders. Next, the hydraulic cylinder is extended to pack the silage material into the test-silo by energizing solenoid S4 (fig. 7). Simultaneously, the single solenoid (S3) on the two-position DCV must be energized to close the valve (used with an open center tractor source).

A string potentiometer attached to the rear of the packing plunger gives feedback on the position of the packing cylinder. When the output reflects a position slightly before the end of full stroke, solenoid S4 is de-energized and solenoid S5 (fig. 7) is energized to retract the cylinder. The cylinder retracts until the string pot output indicates the cylinder is nearly back to its starting position. After packing cylinder retraction, there is a sampling delay (calculated based on the speed, row length, and number of samples entered by the operator); after the delay, the sequence for taking the next sample begins. During the sampling process, the LCD display on the control box continually displays the current system status. Messages inform the operator when a sample is being taken, how long until the next sample will be taken, and what function is occurring ("flap forward," "flap return," "plunger forward," "plunger return"). It also alerts the operator when a silo is full. A full silo is detected if the string potentiometer does not reach an upper threshold value in a set amount of time (e.g., $5 \mathrm{~s}-$ thus indicating the end of stroke was never reached). Once a silo is full, sampling ends. Forage remaining in the collection chute must be removed by manually cycling the packing cylinder with no PVC silo in place.

\section{Testing And Evaluation}

\section{Testing OVerview}

The overall goal for this forage sampling system was to reduce the amount of labor required to collect and package forage crop samples. However, the samples taken must be representative of the crop in the field. Therefore, testing of the sampling system was designed to determine if any bias was induced during sample collection. The criterion for evaluation was similarity of particle size distribution in samples of harvested corn. Testing activities were carried out by chopping corn silage at two locations from 8 to 29 September 2000. The first location was Lamar, Pennsylvania; the second was Rock Springs, Pennsylvania.

\section{EXPERIMENT 1}

Testing on 8 September 2000 focused on comparing the modular sampling system fabricated for this project to a SP plot harvester. The SP plot harvester used a New Holland 707 forage harvester just like the modular system, but it was equipped with a horizontal, batch-type feed mixer with a paddle agitator (speed $\sim 15 \mathrm{rpm}$ ) to keep the chopped forage well mixed. The mixer had a $0.85-\mathrm{m}^{3}$ capacity so that an entire test-plot could be chopped and weighed; it was equipped with two sliding doors on the bottom for collecting samples. Approximate yields from harvested plots ranged from 49.0 to 60.6 Mg/ha. Whole-plant moisture content averaged near $70 \%$ w.b. On a dry matter basis, yields ranged from 14.7 to 18.2 Mg DM/ha. Whole-plant moisture was obtained by chopping entire individual corn plants into a container and then oven drying the material for 24 hours at $103^{\circ} \mathrm{C}$, as per ASAE Standard S358.2 (ASAE Standards, 1999a). 
The side-by-side comparison between the two sampling techniques was carried out by collecting chopped forage from both the modular system and the SP harvester. Four techniques were used to collect samples; their corresponding abbreviations are:

MA = modular system, automatically sampled

$\mathrm{MM}=$ modular system, manually sampled

$\mathrm{SX}=\mathrm{SP}$ harvester, mechanically mixed, then mechanically sampled

$\mathrm{SM}=\mathrm{SP}$ harvester, manually mixed, manually sampled

Five silos were collected for each method. Randomized adjacent rows were used for each treatment, and each silo came from a single row. For the modular unit, the five MA silos were collected using the sampling system, while the five MM silos were collected by chopping forage into a wagon or other container with the collection chute removed, mixing it by hand, and then feeding it into the packing device one grab sample at a time. During collection of the five MA silos from the modular unit, the values used as inputs to the control box were: tractor speed $=1.34 \mathrm{~km} / \mathrm{h}$, row length $=10.7 \mathrm{~m}$, and number of samples $=7$. The flap extension duration was set at $0.25 \mathrm{~s}$. For the SP harvester, SX test-silos were collected by chopping material into the mixer and slowly mixing it for $1.5 \mathrm{~min}$. The sample of chopped forage was emptied out the bottom of the mixer (through a sliding door) and manually placed into a packing chamber (similar to the one on the modular sampling system). SM silos served as a control, similar to the MM silos mentioned above; they were packed by manually mixing silage removed from the mixer and funneling it into the packing chamber one grab sample at a time. The New Holland 707 choppers on both the modular unit and the SP plot harvester were set for $6.35-\mathrm{mm}$ theoretical length of cut (TLC) (all nine cutterhead knives installed). Silos were packed with 4.3- to 6.2-MPa hydraulic pressure in the packing cylinder that exerted 610 to $870 \mathrm{kPa}$ on the forage. Silage density varied from 700 to $900 \mathrm{~kg} / \mathrm{m}^{3}$ yielding silos containing 2.0 to $2.6 \mathrm{~kg}$.

After silos ensiled for 48 days at room temperature, their entire contents were separated into six size fractions using a particle size separator conforming to ASAE Standard S424.1 (ASAE Standards, 1999b). For each silo, the mass of the total sample was recorded, and after separation, the mass of material on each tray of the separator was also recorded. Particle size fractions for all samples were analyzed statistically (via t-tests) to identify significant differences between the two material sampling methods (MA and SX) and their respective controls (MM and SM).

Three different approaches were used to analyze and compare data. In the first approach, individual mass percentages on each of the six trays were compared via t-test. No trends were clear or consistent. In the second approach, the mass percentages from the trays were aggregated into three particle size ranges rather than the measured 6 ranges. The three portions were compared among treatments. The third approach was based on a two parameter Weibull fit to particle size distribution data. In the first two approaches, two-sample t-tests on mean mass percentages were used to check for significant differences in particle size distributions; in the third approach, t-tests were conducted on Weibull parameters. Summaries of $\mathrm{p}$-values are given in tables 1,2 , and 3 .
Table 1. Summary of particle size distributions ${ }^{[a]}$ for corn silage sampled with four methods. ${ }^{[b]}$

Particle Size Range (mm)

\begin{tabular}{ccccccc}
\hline & \multicolumn{5}{c}{ Particle Size Range (mm) } \\
\cline { 2 - 7 } Description & $>26.9$ & $18.0-26.9$ & $8.98-18.0$ & $5.61-8.98$ & $1.65-5.61$ & $<1.65$ \\
\hline SX vs. SM[c] & & & & & & \\
SX-mean & 2.29 & 7.76 & 48.5 & 27.8 & 12.1 & 1.07 \\
SM-mean & 2.19 & 7.31 & 49.3 & 29.4 & 11.2 & 0.65 \\
p-value[d] & NS & NS & NS & $<0.001$ & 0.25 & 0.07 \\
\hline MA vs. MM[e] & & & & & & \\
MA-mean & 2.10 & 6.43 & 40.0 & 31.4 & 17.3 & 2.76 \\
MM-mean & 1.87 & 7.18 & 41.6 & 32.8 & 15.3 & 1.30 \\
p-value & NS & 0.20 & 0.14 & 0.07 & 0.08 & 0.02 \\
\hline SM vs. MM & & & & & & \\
SX-mean & 2.19 & 7.31 & 49.3 & 29.4 & 11.2 & 0.65 \\
MM-mean & 1.87 & 7.18 & 41.6 & 32.8 & 15.3 & 1.30 \\
p-value & 0.11 & NS & $<0.001$ & 0.002 & 0.001 & 0.07 \\
\hline
\end{tabular}

[a] Particle size distributions show mean mass percentages for five samples.

[b] $70 \%$ m.c. w.b., 6.35-mm theoretical length of cut.

[c] SX = SP harvester, mechanically mixed and sampled. SM = SP harvester, control; manually mixed and sampled.

[d] Likelihood of significant difference using t-test, NS if $\mathrm{p}>0.25$.

[e] MA = modular system, automatically sampled.

$\mathrm{MM}=$ modular system, manually sampled.

The SM and MM data sets served as the control data for the SP harvester and modular sampler, respectively; their purpose was to provide a baseline for comparing the "mixing" and "automatic direct" sampling methods. On average, the SM and MM particle size distributions were significantly different, which can most likely be attributed to the fact that two different forage harvesters were used to chop the material, even though they were set for the same TLC. Thus, a direct comparison between the SX and MA data should not be made. However, individual comparisons of SX to SM and MA to MM are still valid.

While low $\mathrm{p}$-values indicated significant statistical differences between SX and SM or MA and MM, the magnitudes of differences were relatively small. It is doubtful if differences of only a few percent in particle size

Table 2. Summary of aggregated particle size distributions ${ }^{[a]}$ for corn silage sampled with four methods.[b]

\begin{tabular}{lccc}
\hline & \multicolumn{3}{c}{ Particle Size Range (mm) } \\
\cline { 2 - 4 } Description & $>18.0$ & $5.61-18.0$ & $<5.61$ \\
\hline SX vs. SM[c] & & & \\
SX-mean & 10.0 & 76.3 & 13.2 \\
SM-mean & 9.50 & 78.7 & 11.8 \\
p-value[d] & 0.23 & 0.04 & 0.18 \\
\hline MA vs. MM[e] & & & \\
MA-mean & 8.53 & 71.4 & 20.0 \\
MM-mean & 9.05 & 74.3 & 16.6 \\
p-value & NS & 0.04 & 0.05 \\
\hline SM vs. MM & & & 11.8 \\
SX-mean & 9.50 & 78.7 & 16.6 \\
MM-mean & 9.05 & 74.3 & 0.002 \\
p-value & NS & 0.004 &
\end{tabular}

[a] Particle size distributions show mean mass percentages for five samples.

[b] $70 \%$ m.c. w.b., 6.35-mm theoretical length of cut.

[c] SX = SP harvester, mechanically mixed and sampled. $\mathrm{SM}=\mathrm{SP}$ harvester, control; manually mixed and sampled.

[d] Likelihood of significant difference using t-test, NS if $\mathrm{p}>0.25$.

[e] $\mathrm{MA}=$ modular system, automatically sampled. $\mathrm{MM}=$ modular system, manually sampled. 
Table 3. Summary of Weibull parameter[a] differences for corn silage sampled with four methods. ${ }^{[b]}$

\begin{tabular}{lcc}
\hline Description & Weibull Slope & $\begin{array}{c}\text { Characteristic Length } \\
(\mathrm{mm})\end{array}$ \\
\hline SX vs. SM[c] & & \\
SX-mean & 2.19 & 13.2 \\
SM-mean & 2.37 & 13.3 \\
p-value $^{[\mathrm{d}]}$ & 0.09 & $\mathrm{NS}$ \\
\hline MA vs. MM[e] & & \\
MA-mean & 1.85 & 11.8 \\
MM-mean & 2.15 & 12.4 \\
p-value & 0.02 & 0.08 \\
\hline SM vs. MM & & 13.3 \\
SX-mean & 2.37 & 12.4 \\
MM-mean & 2.15 & 0.001 \\
p-value & 0.07 &
\end{tabular}

[a] Based on particle size distributions of five samples.

[b] $70 \%$ m.c., w.b., $6.35 \mathrm{~mm}$ theoretical length of cut.

[c] $\mathrm{SX}=\mathrm{SP}$ harvester, mechanically mixed and sampled.

$\mathrm{SM}=\mathrm{SP}$ harvester, control; manually mixed and sampled.

[d] Likelihood of significant difference using t-test, NS if $p>0.25$.

[e] $\mathrm{MA}=$ modular system, automatically sampled.

$\mathrm{MM}=$ modular system, manually sampled .

distributions would result in biologically or chemically significant differences (Marsh and Hamilton, 1978).

The previous methods for evaluating treatment differences elucidate one of the difficulties of comparing treatments: the data is in the form of particle size distribution (six numbers) rather than a single value for each treatment. Fortunately, a consistent distribution, Weibull, fits particle size distribution data for chopped silage (Pitt, 1987). The minimum $r^{2}$ for the fit of the two-parameter Weibull distribution to the data for an individual sample was 0.984 . Thus, less than $1.6 \%$ of the data variation was not explained by using the two Weibull parameters (slope and characteristic length).

Reasoning similar to model validation was used to compare particle size distributions. Predictive models are often validated by comparing the slope and intercept of actual versus predicted data to the values of 1.0 and 0.0 . That is, if the best fit line between actual data and predicted values has a slope not statistically different from 1.0 and an intercept not statistically different than 0.0 , the model is considered valid. Similarly, if the Weibull parameters (slope and length) are no different for particle size distributions between compared treatments, we conclude the particle size distribution is similar. By definition, characteristic length is the length under which $63.2 \%$ of the particle mass falls. The slope, a shape parameter, characterizes the scatter in the distribution; a larger slope suggests less scatter or more uniform particle sizes.

Table 3 contains the results of $t$-test comparisons between Weibull slope and characteristic length between treatments. The comparison between "controls" from each harvester (SM and MM) suggests the harvesters had slightly different resulting distributions. The harvester with the mixer appears to have a particle size distribution with more uniform particle sizes (higher slope) and larger particles (longer characteristic length). Characteristic length was similar between SX and SM ( $p>0.25)$; particle size was slightly more uniform with SM than SX, but this was marginally significant $(p=0.093)$. The automated sampler (MA) yielded a similar characteristic length as the manual sampling (MM) $(\mathrm{p}=0.08$, difference less than $1 \mathrm{~mm}$ ). However, the MA treatment had a broader distribution of particle sizes than the MM treatment (slope difference of $-0.3, p=0.024$ ).

This analysis does not account for any particle size reduction caused by the mixing action inherent in the SX sampling method. Size reduction during mixing (Heinrichs et al., 1999) could be a partial cause of differences between SX and SM samples since SM samples were not mechanically mixed. For this project, particle size was already small after harvest (6.35 mm TLC); the extent of mixer-induced size reduction should have been minimal; however, the potential for size reduction was present.

\section{EXPERIMENT 2}

The experiment was conducted from 15 through 29 September 2000 to test the effectiveness (of obtaining representative samples) of the modular sampling system under different conditions of moisture (relatively wet and relatively dry, approximately 70 and $60 \%$ w.b., respectively) and TLC (6.35 and $19.1 \mathrm{~mm}$ ). The corn variety was Dekalb $585 \mathrm{RR}$ and yield was approximately $9.4 \mathrm{Mg} \mathrm{DM} / \mathrm{ha}$. For each set of conditions, five MA and five MM samples were collected. All samples collected for this experiment were ensiled for 48 days in the PVC mini-silos at room temperature. After 48 days they were opened and their entire contents separated with a particle size separator (ASAE Standards, 1999b). Particle size distributions of MA and MM samples were analyzed for differences using the same three approaches as in Experiment 1.

Two-sample t-tests on mass percentages of six particle size fractions showed significant differences between the distributions of the MA and MM samples, but consistent trends were not evident (table 4). After aggregating mass percentages into three size fractions, $\mathrm{p}$-values from $\mathrm{t}$-tests indicated that significant differences were present for all three sizes, for almost all conditions (table 5). As crop moisture content decreased, the p-values for the "short" size category decreased. In other words, as the crop became drier, the difference in the amount of fine particles in the MA and MM distributions became more significant.

Characteristic length for samples collected with the automated sampler (MA) was lower than the length of manually collected samples in only one case (wet and long, table 6). In all other cases, there was no difference or the length was longer in manually collected samples. Overall, however, the largest difference in characteristic length was small at $1.2 \mathrm{~mm}$. If there was a difference in Weibull slopes of particle size distributions between treatments, it was larger for automatically collected samples (MA); however, the differences were very small (maximum slope difference of 0.22 ). These results suggest that longer particles were collected during manual sampling; furthermore, particle size distribution of hand-collected samples was less uniform than that of the automatically collected samples.

\section{Conclusions}

Although some improvements to the hardware are recommended to increase efficiency and operator-friendliness, the sampling system successfully collected and packed silage samples in test silos. Operational flexibility was provided 
Table 4. Summary of particle size distributions[a] for corn silage sampled from the modular harvester with two methods ${ }^{[b]}$ with varied moisture content and theoretical length of cut.

$$
\text { Particle Size Range (mm) }
$$

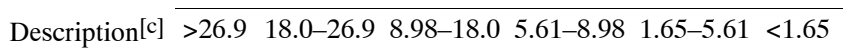
$72 \%, 71 \% ; 6.35 \mathrm{~mm}$

\begin{tabular}{|c|c|c|c|c|c|c|}
\hline MA-mean & 4.23 & 11.6 & 42.4 & 26.2 & 14.4 & 1.21 \\
\hline MM-mean & 2.36 & 8.81 & 43.0 & 29.2 & 15.6 & 1.04 \\
\hline $\mathrm{p}-$-value $[\mathrm{d}]$ & 0.06 & 0.006 & NS & 0.002 & 0.06 & NS \\
\hline \multicolumn{7}{|c|}{$67 \%, 70 \% ; 19.1 \mathrm{~mm}$} \\
\hline MA-mean & 8.45 & 26.3 & 45.3 & 10.5 & 8.61 & 0.77 \\
\hline MM-mean & 11.4 & 28.4 & 40.4 & 9.73 & 8.76 & 1.24 \\
\hline p-value & 0.10 & NS & $<0.001$ & 0.18 & NS & 0.006 \\
\hline \multicolumn{7}{|c|}{$61 \%, 61 \% ; 6.35 \mathrm{~mm}$} \\
\hline MA-mean & 1.71 & 6.22 & 43.5 & 27.2 & 17.6 & 3.74 \\
\hline MM-mean & 2.27 & 7.30 & 39.8 & 26.1 & 19.2 & 5.27 \\
\hline p-value & NS & 0.12 & 0.002 & 0.14 & 0.04 & 0.001 \\
\hline \multicolumn{7}{|c|}{$62 \%, 62 \% ; 19.1 \mathrm{~mm}$} \\
\hline MA-mean & 8.74 & 23.5 & 47.4 & 10.2 & 8.41 & 1.76 \\
\hline MM-mean & 11.0 & 28.4 & 39.3 & 10.2 & 8.82 & 2.41 \\
\hline p-value & 0.12 & 0.04 & 0.005 & NS & NS & 0.06 \\
\hline
\end{tabular}

[a] Particle size distributions show mean mass percentages for five samples.

[b] $\mathrm{MA}=$ modular system, automatically sampled; $\mathrm{MM}=$ modular system, manually sampled.

[c] Moisture of MA, moisture of MM (w.b.), theoretical length of cut.

[d] Likelihood of significant difference using t-test, NS if $p>0.25$.

through adjustable packing pressure and a control system with variable operator inputs and control program constants.

For the comparison of the modular sampling system to a self-propelled plot harvester, samples collected using both the SX (SP harvester, mixed sample) and MA (modular harvester, automatic sampling) techniques had significant differences ( $p-$ values of 0.10 to less than 0.001 ) in particle

Table 5. Summary of aggregated particle size distributions ${ }^{[a]}$ for corn silage sampled form the modular harvester with two methods with varied moisture content and theoretical length of cut.

\begin{tabular}{lccc}
\hline & \multicolumn{3}{c}{ Particle Size Range (mm) } \\
\cline { 2 - 4 } Description[c] & $>18.0$ & $5.61-18.0$ & $<5.61$ \\
\hline $72 \%, 71 \%$; 6.35 mm & 15.8 & 68.5 & 15.6 \\
MA-mean & 11.2 & 72.2 & 16.6 \\
MM-mean & 0.02 & 0.06 & $\mathrm{NS}$ \\
p-value[d] & & & \\
\hline $67 \%, 70 \% ; 19.1 \mathrm{~mm}$ & 34.8 & 55.8 & 9.38 \\
MA-mean & 39.9 & 50.1 & 10.0 \\
MM-mean & 0.02 & 0.002 & 0.20 \\
p-value & & & \\
\hline $61 \%, 61 \% ; 6.35 \mathrm{~mm}$ & 7.93 & 70.8 & 21.3 \\
MA-mean & 9.58 & 65.9 & 24.5 \\
MM-mean & 0.14 & 0.004 & 0.002 \\
p-value & & & 10.2 \\
\hline $62 \%, 62 \% ; 19.1 \mathrm{~mm}$ & 32.3 & 57.6 & 11.2 \\
MA-mean & 39.3 & 49.4 & 0.04 \\
MM-mean & 0.03 & 0.01 & \\
p-value & & & \\
\hline
\end{tabular}

[a] Particle size distributions show mean mass percentages for five samples.

[b] $\mathrm{MA}=$ modular system, automatically sampled; $\mathrm{MM}=$ modular system, manually sampled.

[c] Moisture of MA, moisture of MM (w.b.), theoretical length of cut.

[d] Likelihood of significant difference using t-test, NS if $\mathrm{p}>0.25$.
Table 6. Summary of Weibull parameter ${ }^{[a]}$ differences for corn silage sampled from the modular harvester with two methods ${ }^{[b]}$ with varied moisture content and theoretical length of cut.

\begin{tabular}{lcc}
\hline Description[c] & Weibull Slope & $\begin{array}{c}\text { Characteristic Length } \\
(\mathrm{mm})\end{array}$ \\
\hline 72\%, 71\%; 6.35 mm & 13.6 \\
MA-mean & 2.09 & 12.8 \\
MM-mean & 2.23 & 0.02 \\
p-value [d] & $\mathrm{NS}$ & \\
\hline $67 \%, 70 \% ; 19.1 \mathrm{~mm}$ & & 17.6 \\
MA-mean & 2.07 & 18.7 \\
MM-mean & 1.85 & 0.02 \\
p-value & $<0.001$ & 11.5 \\
\hline $61 \%, 61 \% ; 6.35 \mathrm{~mm}$ & & 11.3 \\
MA-mean & 1.74 & $\mathrm{NS}$ \\
MM-mean & 1.57 & 17.6 \\
p-value & 0.001 & 18.8 \\
\hline $62 \%, 62 \% ; 19.1 \mathrm{~mm}$ & & 0.05 \\
MA-mean & 1.80 & \\
MM-mean & 1.64 & \\
p-value & 0.02 & \\
\hline
\end{tabular}

[a] Based on particle size distributions of five samples.

[b] $\mathrm{MA}=$ modular system, automatically sampled; $\mathrm{MM}=$ modular system, manually sampled.

[c] Moisture of MA, moisture of MM (w.b.), theoretical length of cut.

[d] Likelihood of significant difference using t-test, NS if $p>0.25$.

size distributions compared to their respective controls (SM - SP harvester with manual sampling and MM - modular harvester with manual sampling). Though there were slight, yet statistically significant differences, it was not possible to conclude which technique (SX or MA) provided more representative sampling.

For the evaluation of the modular sampling system, significant differences ( $\mathrm{p}$-values from 0.10 to less than 0.001) were found in the particle size distributions of automatically sampled (MA) and manually sampled (MM) silos. Examining p-values exclusively, automatic direct sampling from the crop stream did not always give samples of material similar to manual sampling. Fine particles tended to be less representatively sampled as crop moisture decreased. No other discernable trends regarding when direct sampling was not representative were evident. However, since the magnitudes of actual differences between means were fairly small (usually less than about 5\% for mass percentages and $1.5 \mathrm{~mm}$ for particle sizes), the impact on biological/chemical differences is likely to be slight. The random, objective sampling of "all of the stream part of the time" was more consistent than manual sampling.

Future evaluation of sampling systems should focus on differences in chemical analyses in addition to particle size. Differences in parameters such as neutral detergent fiber, acid detergent fiber, crude protein, crude fiber, and digestible dry matter should be investigated. Further testing should be conducted with not only chopped corn silage, but also hay crop silage.

For this study, the manual sampling (MM) method was used as a benchmark to determine if automatic sampling (MA) directly from the crop stream was representative. A potential problem with this method is that control samples themselves may be, in fact, not representative. Additional means are needed to obtain and characterize truly representa- 
tive samples of chopped forage that can serve as benchmarks for alternative methods.

\section{ACKNOWLEDGEMENTS}

The authors would like to thank Jeff McClellan, Duane Dorman, Steve Walker, Trevor Rudy, Eric Greenawalt, Mike Sword, Rod Thomas, and the Penn State Agronomy Farm staff for their help with this project. Their assistance was very much appreciated.

\section{REFERENCES}

Allen, R. J. Jr., T. W. Casselman, and F. H. Thomas. 1968. An improved forage harvester for experimental plots. Agronomy Journal 60(5): 584-585.

ASAE Standards, 46th Ed. 1999a. S358.2. Moisture measurements - Forages. St. Joseph, Mich.: ASAE.

. 1999b. S424.1. Method of determining and expressing particle size of chopped forage materials by screening. St. Joseph, Mich.: ASAE.

Austenson, H. M. 1958. Use of a field chopper for harvesting forage plots. Agronomy Journal 50(4): 231-231.

Barnes, G. L., G. L. McLaughlin, W. D. Foster, and W. E. McMurphy. 1984. A modified flail mower for harvesting forage research plots. Agronomy Journal 76(6): 1022-1023.

Buker, R. J. 1967. Forage plot harvester. Agronomy Journal 59(2): 203-204.

Caddel, J. L., D. G. Batchelder, and G. L. McLaughlin. 1982. Forage plot clipping wagon to improve harvesting efficiency. Agronomy Journal 74(6): 1098-1099.

Collins, K. L., C. L. Rhykerd, and C. H. Noller. 1969. A self-propelled experimental plot forage harvester. Agronomy Journal 61(2): 338-339.

Frerichs, R., R. Brentlinger, C. A. Shapiro, and R. S. Moomaw. 1993. One-row machine for the harvest of corn stover. Agronomy Journal 85(5): 1096-1097.

Heinrichs, A. J., D. R. Buckmaster, and B. P. Lammers. 1999. Processing, mixing and particle size reduction of forages for dairy cattle. J. Animal Science 77(1):180-186.
Hunter, A. S., L. D. Hoffmann, G. W. Allshouse, and W. L. Kjelgaard. 1974. Portable self-propelled field plot forage chopper for agronomic research. Agronomy Journal 66(2): 594-596.

Kraus, T. J., R. G. Koegel, K. J. Shinners, and R. J. Straub. 1993. Design and evaluation of a side dumping/weighed container wagon for forage harvesting research. ASAE Paper No. 931579. St. Joseph, Mich.: ASAE.

Mains, W. H., and D. J. Major. 1983. Adaptation of a forage harvester for harvesting small plots. Canadian Journal of Plant Science 63(4): 1057-1060.

Marsh, R., and P. B. Hamilton. 1978. A review of the effects of mechanical treatment of forages on fermentation in the silo and on the feeding value of the silages. N.Z.J. of Experimental Agriculture 6(4): 271-278.

McCormick, R. F. Jr., and C. S. Hoveland. 1971. The Auburn small-plot forage harvester. Agronomy Journal 65: 951-952.

Miltimore, J. E., A. D. McMechan, and J. C. Wilcox. 1961. A self-propelled plot forage harvester. Agronomy Journal 53(3): 206-207.

National Agricultural Statistics Service (NASS). 2001. Pennsylvania Agricultural Statistics Service: Published Estimates Database. Available: http://www.nass.usda.gov/pa. Accessed 15 March 2001.

National Research Council. 2001. Nutrient Requirements of Dairy Cattle, seventh revised edition. Washington D.C.: National Academy Press.

Paterson, J. J., and D. R. Browning. 1962. Hydraulic self-propelled forage plot harvester. Agricultural Engineering 43(5): 270-271, 291.

Pearson, C. H., and L. Robinson. 1994. Automating a commercial swather for harvesting forage plots. Agronomy Journal 86(6): 1131-1132.

Pedersen, J. F., and K. J. Moore. 1995. An automated plot harvest system for use with a commercial forage harvester. Agronomy Journal 87(3): 605-607.

Pitt, R. E. 1987. Theory of particle size distributions for chopped forages. Transactions of the ASAE 30(5): 1246-1253.

Swallow, C. 1967. Self-propelled plot forage harvester. Agronomy Journal 59(6): 609-610. 